\title{
Ovarian Mucinous Cystic Tumor with Mural Nodules
}

National Cancer Institute

\section{Source}

National Cancer Institute. Ovarian Mucinous Cystic T umor with Mural Nodules. NCI

Thesaurus. Code C40042.

A mucinous cystic tumor of the ovary characterized by the presence of one or more well circumscribed solid nodules in the wall of the cysts (mural nodules) that protrude into the lumen. The mural nodules may be benign (sarcoma-like) or malignant. The malignant mural nodules histologically are anaplastic carcinomas, carcinosarcomas, or sarcomas. The clinical course depends on the histology of the mural nodules. The prognosis of mucinous cystic tumors with benign mural nodules is the same as the corresponding types of mucinous cystic tumors without the mural nodules. Mucinous cystic tumors with malignant mural nodules may follow a malignant clinical course. 